\title{
The Role of TQM Approach in Indonesia Higher Education Quality Assurance
}

\author{
Steaven Octavianus ${ }^{1}$, Reni Triposa ${ }^{2}$, Dwi Novita Sari ${ }^{3}$, \\ Yonathan Yakup Mononimbar ${ }^{4}$, Teguh Parluhutan ${ }^{5}$ \\ Sangkakala Theological Seminary, Salatiga-Kopeng KM 7, Getasan, Semarang Districts, \\ Central Java Indonesia ${ }^{1,2,3,4,5}$ \\ \{stev.oct@gmail.com¹, renitriposa@sttsangkakala.ac.id², keziadwinovitasari@gmail.com³, \\ jonathan.mono10@gmail.com ${ }^{4}$, teguh.epafras@gmail.com ${ }^{5}$ \}
}

\begin{abstract}
The high expectation that Indonesian tertiary education graduates will be able to provide human resources is certainly a projection to face the demographic bonus in the future. Therefore, universities need to prepare the quality of their management. The TQM approach is a quality approach used in the internal quality assurance system of higher education institutions in Indonesia. The TQM approach is an approach that is oriented towards customer satisfaction and continuous improvement. In this system, universities prioritize continuous improvement and customer satisfaction. The estuary of this overall quality assurance lies in the implementation of a quality culture.
\end{abstract}

Keywords: TQM; Higher Education; Quality

\section{Introduction}

The development of science, technology, and art has had various impacts on various sectors of life. The era of disruption with the 4.0 industrial revolution triggered change and innovation [1]. This disruptive change also affects the world of education. Despite of some weaknesses, Indonesia is quite ready in terms of internet databases to face the industrial revolution 4.0 in the world of education [2]. In welcoming this era of disruption, higher education institutions have a significant role to build well-qualified human resources with undergraduate qualifications.

The high expectation that Indonesian tertiary education graduates will be able to provide human resources is certainly a projection to face the demographic bonus in the future. Based on BPS (Statstical Central Bureau) data, unemployment at the college graduate level is $13.17 \%$ [3]. The number of unemployed in Indonesia is 9.77 million people. With a rate of $13.17 \%$, the total number of unemployed contributed by college graduates was $1,286,709$ people. Although the unemployment rate in the labor force originating from college graduates is lower than secondary and basic education, this number is still quite high. Thus, tertiary institutions need to prepare all the qualities to adapt their needs industrial world.

The needs and qualifications of the working world and a disrupted industry will always change. Mastery over big-data analysis is now a natural thing to have. The ability to master technology and foreign languages is something that cannot be negotiated. Therefore, 
universities need to prepare the quality of their management. Through Law number 12 of 2012 , it is stated that universities are required to have an internal quality assurance system to ensure the quality of their institutions [4]. This law is also supported by the regulation of the minister of education and culture number 50 of 2014 concerning the higher education quality assurance system [5]. Based on these laws and regulations, the internal quality assurance system for higher education is a non-negotiable obligation.

Quality assurance cannot be separated from the Total Quality Management (TQM) approach. Through the TQM approach, satisfaction will be realized by both internal and external customers at educational institutions [6]. In education, internal customers are educators, education staff, and students. Meanwhile, external customers are parents, stakeholders, the community to the government. Satisfied internal customers will provide excellent service. Excellent service will lead to external customer satisfaction [7]. In principle, the internal quality assurance of a higher education institution will determine the service of the college and it will determine customer satisfaction. Quality services in higher education will increase student satisfaction [8]. Satisfied students will give testimonials which will boost the university reputation. This customer satisfaction is one of the the principles of TQM approach. Therefore existing internal quality assurance can rely on this approach.

The TQM approach is a quality approach used in the internal quality assurance system of higher education institutions in Indonesia [9]. The quality culture will be implemented in higher education by focusing on customer satisfaction and continuous improvement. Referring to the regulation of the minister of education and culture number 50 of 2014, the quality assurance system in Indonesia adheres to the PPEPP cycle, stipulation, implementation, evaluation, control, and improvement. From this cycle, it can be seen that the TQM approach is the foundation of quality assurance in Indonesia. Based on these facts, this study will look at the role of the TQM approach in the internal quality assurance system in Indonesian universities.

\section{Method}

This is a descriptive qualitative research by using the literature analysis method. The references are various findings of research journals regarding TQM in higher education which analyzed by the conditions of the existing laws and regulations in Indonesia. Based on this analysis, it would be found how the role of TQM in the internal quality assurance system of universities in Indonesia. An input strategy will be made so that the existing internal quality assurance system can be implemented in all forms of tertiary institutions in Indonesia.

\section{Analysis and Discussion}

\subsection{TQM}

The world of education is complex because for its various result. Therefore, the application of TQM in education requires a special strategy [10], [11]. The results of this education are not as clear as the industrial world. High scores do not necessarily correspond to planning. The indicators and variables are not as clear as in the industrial world. In his writing, Jagiello states that there are many arguments and debates regarding the implementation of TQM in education [12]. Educational institutions prepare students as input to become graduates who can have an 
impact on society with the knowledge and skills that have been acquired while in educational institutions.

Similar to other educational institutions, higher education institutions also process students to have knowledge and skills to become graduates who can have an impact on society. Higher education institutions even prepare students to immediately enter the community after graduating as experts, skilled workers and professionals, and academics. For this reason, TQM is an approach that can be implemented in the world of higher education [13] - [15]. Jackson and Sabet's study shows the possibility of TQM in its implementation in higher education institutions.

\subsection{TQM in Higher Education}

Several studies have been conducted to see how TQM is implemented in higher education [13], [15] - [17]. Other research on the implications of quality management was carried out by Eryilmaz et al (2016) regarding quality management in higher education. This study examined quality management at 197 higher education institutions in Turkey. The result is $47 \%$ of respondents stated that their institution had quality management certification. Based on these findings, it can be said that even though quality management has been implemented in high schools in Turkey, the task for quality development still seems to require more effort. This can be seen from the many higher education institutions that have not been certified for quality management. The existing certification is part of the process of controlling and proving the implementation of quality management in the institution.

Furthermore, a study conducted by Sabet et al (2012) which took the subject of 112 lecturers from five well-known universities in Malaysia found how the TQM concept could be translated into the teaching and learning process in higher education. Commitment and cooperation are two important keys in implementing TQM which provide many benefits for the organization. Cooperation and mutual commitment can develop creativity, ability, speed, and assistance from staff. However, it was found that even though many lecturers knew TQM, they mostly did not understand how to implement it in their teaching. For this reason, institutions need to allocate special funding to develop knowledge and capabilities for this. This recommendation is in line with Rowley and Ishijima's who stated that it is very important for all staff in higher education institutions to understand their role in holding quality in student learning [18], [19]. Although sometimes the mechanisms and frameworks that exist in one institution and another are different, the quality issue is something that deserves to be underlined [20]. In this case, the integrated TQM has been running, but what is needed next is to find out the extent of the integration and implementation of TQM in a tertiary institution.

\subsection{Quality Assurance in Indonesian Universities}

The implementation of TQM in higher education institutions cannot separated from quality assurance for the implementation of the quality management system that is implemented. Quality assurance will see how far the success of quality management has been implemented in the higher education system. In the quality assurance system, it will be known as quality assurance carried out internally and quality assurance carried out by externals. Internal quality assurance is carried out by the institution itself, while external quality assurance is carried out by institutions outside the institution. In their research, Adamu \& Addamu (2012) found that internal quality assurance in the form of "internal audit" and accreditation, which are external quality assurance, are important elements in the higher education quality assurance system in 
Ethiopia [21]. The main objective of a quality assurance system in higher education based on Adamu research is to maintain and develop the quality of the higher education institution. Internal and external evaluation will be able to maintain the quality or quality of higher education institutions and develop it.

Internal audit plays an important role in the internal quality assurance system in higher education institutions. This important role is evidenced by Kettunen's (2012) research on internal and external auditing in higher education institutions [16]. In his research, Kettumen found that the audit process would help the institution to take corrective action to improve the process or maintain it. Through these findings, it can be said that an audit which is an evaluation and part of quality assurance can help to maintain a management process in an institution and correct errors, and even improve it. The external and internal audit process helps the institution to improve its quality on an ongoing basis. Furthermore, in his findings, Kettumen stated that the main weakness of external audit is in the management process. Internal audit should focus on the process or quality deviations that exist in the management process. If any irregularities are found, the leadership may hold a meeting with the team responsible for the process to determine a corrective action plan. Looking at the findings, the implementation of audit actions based on quality management requires commitment and participation from various parties for its implementation. Even though the audit is an evaluation step, it still requires TQM to be able to guarantee its quality management.

Self-assessment in the form of an internal audit needs to be carried out when an institution wants to see how its management process is being achieved. Public and private higher education institutions can do this in the same way. Cardo so et al (2017) found that higher education institutions need to find an internal assessment model that suits itself [22]. Most of the higher education institutions simply take without modifying the variables and selfassessment indicators of the quality management system that exists in Europe [22]. This will not suit the needs of the college. Therefore, higher education institutions should make a selfassessment system under the conditions and situation.

In Indonesia, internal quality assurance has a very big role in the management of higher education [23]. This is stated in law number 12 of 2012 and Permendikbud number 50 of 2014 [4], [5] whereas higher education quality standards are regulated through the minister of education and culture regulation number 3 of 2020 [24]. These existing laws and regulations have proven the importance of quality assurance in universities in Indonesia. The diversity of types of tertiary institutions in Indonesia requires different types of internal quality assurance systems [25], [26]. Thus the existing quality assurance will be by the needs and values of the existing higher education organizations.

\subsection{Internal Satisfaction}

Research on customer satisfaction aims to determine how satisfied customers are with the performance of the institution. Customer satisfaction is a paradigm that is quite important, because by knowing how satisfied an institutional customer is, the institution will know its performance. The quality paradigm becomes a paradigm that becomes the basis for implementing services for customer satisfaction [27]. This satisfaction mapping can be carried out by internal institutions and people from outside the institution. One of these studies was carried out by Temizer et al (2012) which aims to develop and test a Student Satisfaction Index [28]. Student satisfaction is assessed from a variety of different aspects, such as school description, expectations, the quality obtained, the scores obtained, the level of satisfaction, and the overall loyalty of the students. The measurement carried out by Temizer is based on 
the ECSI (European Customer Satisfaction Index) provided for Higher Education. Based on the research results, if the school management wants to increase student satisfaction and loyalty, they must focus on the quality of the products and services they provide and the image of the school from the student's point of view. This research conducted by Temizer strengthens the writing of Cardoso et al. (2017) which states that many internal performance measurements focus on standards originating from Europe. This European standard tends to be generalized in its use to measure the achievement of quality management performance in higher education institutions. In conclusion, Cardoso et al emphasized how higher education institutions together with external assessors can provide space for institutions to develop a framework based on the uniqueness of the institution. The internal quality assurance which is based on the uniqueness and nature of an institution will of course provide added value and refers to the continuous improvement and success of TQM in the institution.

One of the studies related to the quality of the internal quality assurance system which is based on the uniqueness of the institution is the research of Noda (2018) on the restructuring of the quality assurance framework in higher education [29]. wherein his findings Noda stated that two universities in Japan and Taiwan should maintain transparency to maintain the quality of their institutions. Satisfaction from students will make them loyal to higher education institutions [8], [30], [31]. Looking at the research, the adaptation of the TQM standard used is adjusted to the conditions of existing higher education institutions and continues to be oriented towards customer satisfaction.

Internal assessments goes together with separated from external assessments. External assessment is an assessment or evaluation carried out by parties outside the educational institution. This assessment can be carried out by the government or by an external assessor who has been previously appointed by the educational institution. As in the internal quality assurance in England which is implemented by QAA (Quality Assurance Academy) [32]. External assessment can be a stimulus for institutions to control their quality management through internal assessments [22]. External assessment or institutions that do this are institutions that set and monitor standards for higher education institutions, such as those implemented by the QAA in higher education institutions in the UK [32]. For this reason, both external and internal assessments are an integral part of the implementation of TQM which is in the assessment and quality control section of quality management practices in an educational institution.

\subsection{Theoretical Models}

The TQM approach is an approach that exists in the business world. When this approach is applied in the world of education, several management theories are borrowed here to make adjustments [33]. Based on the above studies, the authors provide an overview of the application of TQM in tertiary institutions as follows:

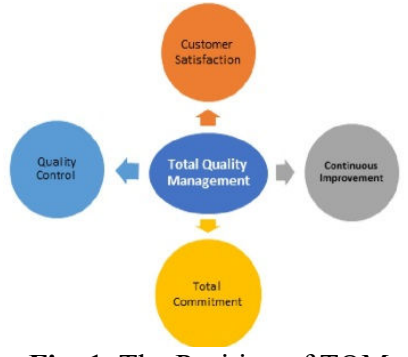

Fig. 1. The Position of TQM 
TQM is an approach that includes customer satisfaction, continuous improvement, shared commitment, and quality control to implement quality management in higher education [34], [35]. To implement these things, a university needs to carry out self-evaluation of internal quality audits that are based on standardization of external quality audits [16], [36]. External audits at higher education institutions constitute accreditation. Accreditation will be the face of quality for higher education to be seen by the public so that universities need to continue to improve their quality [37], [38], [39].

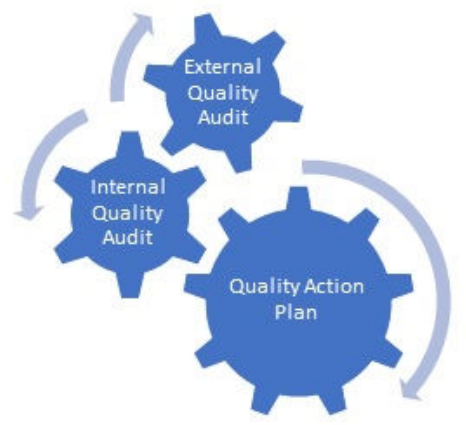

Fig. 2. Position of Internal and External Quality Audit

When establishing a quality action plan, higher education institutions need to base it on the standardization of external quality audits or accreditation and also the results of previous internal quality audits. Like a loop in the quality action plan process, this will also be a benchmark for the internal quality audit that is carried out. But of course, even though the institution will be assessed from an external quality audit based on standardization based on quality standards that come from the business world, higher education institutions still need to make adjustments to their institutional needs to comply with the TQM principles in their institutions [40]. To achieve compliance with TQM in educational institutions, the authors propose a quality management process as follows:

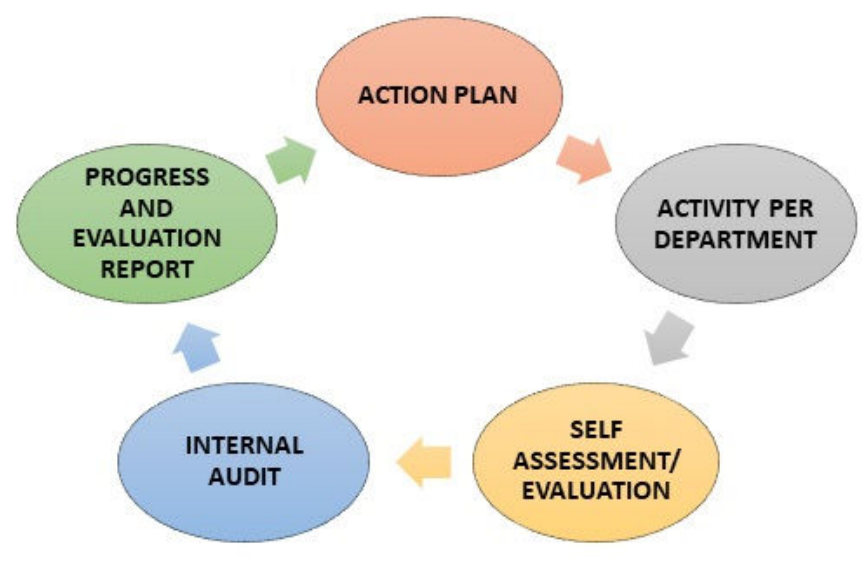

Fig. 3. Proposed Model for Internal Quality Assurance 
In the above process, a quality audit is carried out after the departments within the institution carry out a self-assessment. After a quality audit is carried out when there are standards that are not met, a corrective action plan is made. In fulfilling the corrective action plan, the department evaluates the progress of the improvements to the quality assurance agency. Improvement assistance is carried out jointly so that its achievements are monitored and after these achievements are implemented, the department makes a new developmental action plan. Through this cycle, TQM elements such as customer satisfaction to continuous improvement and quality development will be achieved because a joint commitment to the leadership and all departments is needed here.

\section{Conclusion}

The TQM approach is an approach that is oriented towards customer satisfaction and continuous improvement. Although this approach is widely used in the business world, this approach can also be used in the world of education. Various studies have proven the possibility of using the TQM approach in education. In Indonesia, the TQM approach is used in the higher education quality assurance system. In this system, universities prioritize continuous improvement and customer satisfaction. The estuary of this overall quality assurance lies in the implementation of a quality culture. The quality culture that is implemented will improve the higher education services, the increased service will continue to make universities survive and even develop during the disruption. For this reason, the role of TQM in the internal quality assurance system in Indonesia is an implementation basis that will continue to be developed.

\section{References}

[1] KN Kalu, "The impact of ICT-diffusion on government effectiveness: what role for cultural practices?," Int. J. Organs. Theory Behav. , vol. 22, no. 2, pp. 123-154, 2019, doi: 10.1108 / IJOTB-07-2018-0087.

[2] A. Reginasari and V. Annisa, "Exploring Experiences Using Internet-Based Technology in Preparing Indonesia for Industry 4.0," J. Researcher. Wisdom. Educator. , vol. 11, no. 3, pp. 183-196, 2019, doi: 10.24832 / jpkp.v11i3.211.

[3] Sub-directorate of Statistical Analysis, National Employment Survey. Jakarta: BPSStatistics Indonesia, 2020.

[4] Law number 12 of 2012 concerning Higher Education. Indonesia, 2012.

[5] Permendikbud Number 50 of 2014 concerning Higher Education Internal Quality Assurance Systems. Indonesia, 2014.

[6] E. Sallis, Total quality management in education: Third edition. 2014.

[7] F. Tjiptono, Service Management: Delivering Excellent Service . Yogyakarta: ANDI, 2017.

[8] F. Hartanto, Rusdarti, H. Yanto, and A. Purwanti, "The Effect of Service Quality, Campus Ecology, and Self-Efficacy on Students' Satisfaction in Anaa Specialist Education Program, Diponegoro University Semarang," J. Educ . Dev., vol. 7, no. 2, pp. 117-125, 2019.

[9] A.. Soegito, Total Quality Management (TQM) in Higher Education . Semarang: UNNES Press, 2011. 
[10] A. Zalejska-Jonsson, "Does facility management affect perception of building quality ?,” vol. 38, no. 37518, pp. 559-576, 2020, doi: 10.1108 / F-02-2019-0026.

[11] P. Chuah, P. Lim, and G. Town, "Applying quality tools to improve student retention supporting processes: a case study from WOU," vol. 13, no. 1, pp. 60-72, 2018, doi: 10.1108 / AAOUJ-01-2018-0003.

[12] U. Jagiello, "The problem of fear in TQM - causes, consequences and reduction methods - a literature review," vol. 32, no. 6, pp. 1217-1239, 2020, doi: 10.1108/ TQM-02-2019-0047.

[13] N. Jackson, "Internal academic quality audit in UK higher education: part II implications for a national quality," TQM J., 2012.

[14] N. Jackson, "Internal academic quality audit in UK higher education: part I - current practice and conceptual," 2012.

[15] HS Sabet, ZS Saleki, B. Roumi, and A. Dezfoulian, "A Study on Total Quality Management in Higher Education Industry in Malaysia," Int. J. Bus. Soc. Sci. , vol. 3, no. 17, pp. 208-215, 2012.

[16] J. Kettunen, "External and internal quality audits in higher education," TQM J., vol. 24, no. 6, pp. 518-528, 2012, doi: 10.1108 / 17542731211270089.

[17] ME Eryilmaz, E. Kara, E. Aydogan, O. Bektas, and DA Erdur, "Quality Management in the Turkish Higher Education Institutions: Preliminary Findings," Procedia - Soc. Behav. Sci. , vol. 229, pp. 60-69, 2016, doi: 10.1016 / j.sbspro.2016.07.114.

[18] J. Rowley, "A new lecturer's simple guide to quality issues in higher education," pp. 2 7, 1999.

[19] H. Ishijima and JM Mshana, "The '5S' approach to improve a working environment can reduce waiting time Findings from hospitals in Northern Tanzania," 2015, doi: 10.1108 / TQM-11-2014-0099.

[20] AH Abdullah, S. Wasiuzzaman, and R. Musa, "University quality and emotional attachment of undergraduate students in a private higher education in Malaysia," Int. J. Soc. Econ., vol. 42, no. 7, pp. 644-665, 2014, doi: 10.1108 / IJSE-03-2014-0050.

[21] AY Adamu and AM Addamu, "Quality assurance in Ethiopian higher education: Procedures and practices," Procedia - Soc. Behav. Sci. , vol. 69, no. Iceepsy, pp. 838846, 2012, doi: 10.1016 / j.sbspro.2012.12.006.

[22] S. Cardoso et al., "Internal quality assurance systems: 'tailor made' or 'one size fits all' implementation ?," Qual. Assur. Educ., vol. 25, no. 3, pp. 329-342, 2017, doi: 10.1108 / QAE-03-2017-0007.

[23] B. Academic, D. General, P. Tinggi, and National DP, "Guidelines for the implementation of the higher education quality assurance system (spm-pt)," 2006.

[24] Regulation of the Minister of Education and Culture of the Republic of Indonesia Number 3 of 2020 concerning National Higher Education Standards. Indonesia, 2020.

[25] ES Kurniatun, M. Rachman, Masrukhi, and Rusdarti, "Developing a Model of SN-PTBased Internal Academic Quality Assurance System in the Educational Training Institution of the Military Academy Magelang," J. Educ. Dev. , vol. 5, no. 2, pp. 284296, 2017.

[26] S. Octavianus, Y.. Sukestiyarno, Rusdarti, and E. Pramono, Suwito, "Improving Theological Seminary Human Resources' Quality Mind-Set in Disruption Era," Jun. 2020, [Online]. Available: https://dx.doi.org/10.2991/assehr.k.200620.077.

[27] IS Mohammad and CF Oduoza, "Lean-excellence business management for manufacturing SMEs focusing on KRI," Int. J. Product. Perform. Manag. , vol. 69, no. 3, pp. 519-539, 2019, doi: 10.1108 / IJPPM-11-2018-0389. 
[28] L. Temizer and A. Turkyilmaz, "Implementation of student satisfaction index model in higher education institutions," Procedia - Soc. Behav. Sci. , vol. 46, pp. 3802-3806, 2012, doi: 10.1016 / j.sbspro.2012.06.150.

[29] A. Noda, AYC Hou, S. Shibui, and H.-C. Chou, "Restructuring quality assurance frameworks A comparative study between NIAD-QE in Japan and HEEACT in Taiwan," High. Educ. Eval. Dev. , vol. 12, no. 1, pp. 2-18, 2018, doi: 10.1108 / HEED12-2017-0008.

[30] KSM Appuhamilage and H. Torii, "The impact of loyalty on the student satisfaction in higher education A structural equation modeling analysis," High. Educ. Eval. Dev. , vol. 13, no. 2, pp. 82-96, 2019, doi: 10.1108 / HEED-01-2019-0003.

[31] S. Annamdevula and Bellamkonda Hospital, "Effect of student perceived service quality on student satisfaction, loyalty and motivation in Indian universities of Development of HiEduQual," J. Model. Manag. , vol. 11, pp. 488-517, 2016, doi: 10.1108 / JM2-01-2014-0010.

[32] A. Felce, "Managing the quality of higher education in apprenticeships Managing the quality of higher education in apprenticeships," High. Educ. Ski. Work. Learn. , vol. 9, no. 2, pp. 141-148, 2019, doi: 10.1108 / HESWBL-10-2018-0106.

[33] M. Moeini and B. Simeonova, "Theory borrowing in IT-rich contexts: Lessons from IS strategy research," 2020, doi: 10.1177 / 0268396220912745.

[34] SE Pramono, B. Solikhah, DV Widayanti, and A. Yulianto, "Strategy to Improve Quality of Higher Education Institutions Based on AUN-QA Standard," Int. J. Innov. Educ. Res. , vol. 6, no. 09, pp. 141-152, 2018.

[35] A. Allaoui and R. Benmoussa, "Employees' attitudes toward change with Lean Higher Education in Moroccan public universities," J. Organ. Chang. Manag. , vol. 33, no. 2, pp. 253-288, 2020, doi: 10.1108 / JOCM-08-2018-0232.

[36] AA Oussii and NB Taktak, "The impact of internal audit function characteristics on internal control quality," Manag. Audit. J. , vol. 33, 2011, doi: 10.1108 / MAJ-06-20171579 .

[37] SA Makhoul, "Higher education accreditation, quality assurance and their impact to teaching and learning enhancement," J. Econ. Adm. Sci. , vol. 35, no. 4, pp. 235-250, 2019, doi: 10.1108 / JEAS-08-2018-0092.

[38] G. Motova and V. Navodnov, "Twenty years of accreditation in Russian higher education: lessons learned," High. Educ. Eval. Dev. , vol. 05, pp. 23-42, 2019, doi: 10.1108 / HEED-05-2019-0023.

[39] Rusdarti and S. DWP, "Accountability of Quality Assurance Against Accreditation of Study Programs at the Postgraduate Program of the State University of Semarang," Educ. Ma , vol. 6, no. 2, pp. 196-207, 2017.

[40] SEP Dedi Prestiadi, Wahyu Hardyanto, "IMPLEMENTATION OF TOTAL QUALITY MANAGEMENT (TQM) IN ACHIEVING STUDENT SATISFACTION," Educ. Manag. , vol. 4, no. 2, pp. 107-115, 2015, [Online]. Available: http://journal.unnes.ac.id/sju/index.php/eduman\%0A. 